\title{
ANTIOXIDANT ACTIVITY OF GREEN COFFEE COMMERCIAL PRODUCTS
}

\author{
Filipe do Carmo Aleixo de Sousa2 (aleixo.sousa91@ gmail.com); Érika Fraga de Souza1, \\ 2; Otniel Freitas-Silva1,2.
}

1 - Embrapa Agroindústria de Alimentos, Brasil.

2 - Programa de Pós Graduação em Alimentos e Nutrição (PPGAN) - Universidade Federal do Estado do Rio de Janeiro (UNIRIO)

Several benefits have been attributed to the consumption of green coffee, in the form of capsules or teas, mainly due to its high phenolic acid content or to its antioxidant, antimutagenic and anticarcinogenic activity in vitro. Green coffee is composed of a variety of polyphenols which correspond to 6 to $10 \%$ of the dry weight, and within the group of chlorogenic acids, the caffeinoylquimic acids are the majority. Different compounds presented in coffee are related to a chemoprotective effect in biological and chemical systems, justified by the presence of phenolic compounds, such as chlorogenic acids. The principal form of consumption of the coffee beverage is predominantly in the form of infusion of roasted and grounded coffee; lately the green coffee extract has gained a share of the market by the appeal of health, mainly because it is richer in chlorogenic acids than the traditional drink. In this sense the objective of the study was to evaluate the antioxidant activity of different green coffee extracts products and brands. The green coffee products analyzed in this work were purchased directly from the local trade: Samples 1 to 3 in the form of capsules and Sample 4 in the form of flour to be added in the food, and a product purchased in the United States of America (USA) in capsule form (sample 5). For the extraction of the bioactive compounds from the green coffee products, $10 \mathrm{~g}$ of the green coffee product was weighed and mixed with $150 \mathrm{ml}$ of distilled water, then the products were brought to a tip ultrasound for 10 minutes with an initial power of $200 \mathrm{w}$. The samples were centrifuged at $7000 \mathrm{rpm}$ for 14 minutes, further diluted in sodium phosphate buffer $\mathrm{pH}$ 7.4. The antioxidant activity was performed through the ORAC methodology as described by ZULETA; ESTEVE; FRÍGOLA (2009). The results obtained were 64.75, 99.45, 1.452,58, $860,63,1858.12 \mu \mathrm{mol}$ trolox/g for samples 1 to 5 , respectevely. The commercial product with the highest potency of antioxidant activity, by the in vitro ORAC analysis methodology, based on the recommendations of the manufacturers of daily intake, was the product 4 with a total of $51.637,8 \mu \mathrm{mol}$ equivalent to trolox, with about 5 times more Antioxidant activity tnhan the product 5 which presented results of $9587,9 \mu \mathrm{mol}$ trolox equivalent per day. The daily intake recommended by the manufacturers of products 3,2 and 1 results in a consumption of antioxidants equivalent to trolox per day of: $6,798 \mu \mathrm{mol} ; 218.79 \mu \mathrm{mol}$ and $142.45 \mu \mathrm{mol}$, respectively. Although the level of antioxidant activity in the green coffee extracts presented stability as antioxidant activity, other chromatographic and PCR analyses are being conducted in these samples in order to verify the authenticity, quality and safety of green coffee extracts. 